\title{
Comparison of the Influence of Process Fluids on Tool Life in Face Milling
}

Jan Jersák, František Kaplan

Department of Machining and Assembly, Faculty of Engineering, Technical University of Liberec, Studentská 2, 46117 Liberec, Czech Republic.E-mail: jan.jersak@tul.cz, frantisek.kaplan@post.cz

Thanks to their chemical and mechanical properties, the process fluids (PFs) can significantly affect the process of machining [2], [15], [16], [18]. It is particularly important that PFs should positively influence the quality of the machined surfaces of machine parts and durability of cutting tools [4], [5], [6], [7], [10], [11], [12], [14]. Other significant factors in PFs are economic and environmental [17]. The costs of the acquisition, use and disposal of PFs must not be too high. As part of the research project in collaboration with the company Paramo, a.s. and the Technical University of Liberec, completely new environment-friendly PFs (labeled as PF01, PF02, PF03, PF04, and PF05) have been developed and evaluated. In the Laboratory of Machining at the Technical University of Liberec, the effects of these new PFs were examined from a viewpoint of a number of technological aspects. This article presents the results of experiments conducted on structural steel $16 \mathrm{MnCr} 5$ and stainless steel X2CrNiMo1814-3 face milling using these newly developed eco-PFs.

Keywords: machining, milling, process fluid, environment-friendly, tool durability

\section{Acknowledgement}

This article was realized under the financial support of state budget of the Czech Republic - the Technology Agency of the Czech Republic (within the research project TA02021332).

\section{References}

[1] BRYCHTA, J., ČEP, R., NOVÁKOVÁ, J., PETŘKOVSKÁ, L. (2007). Technologie II - 1. díl. Ostrava: VŠB TU Ostrava. ISBN 978-80-248-1641-8.

[2] BAKALOVA, T., LOUDA, P., VOLESKÝ, L., BORU゚VKOVÁ, K., SVOBODOVÁ, L. (2015). Nanoadditives $\mathrm{SiO}_{2}$ and $\mathrm{TiO}_{2}$ in Process Fluids. Manufacturing Technology. Vol. 15, September, No. 4. s. 502 - 508. ISSN 12132489.

[3] ČSN ISO 8688-1. Testovanie trvanlivosti pri frézovaní, Čast' 1: Rovinné frézovanie. 1993. Praha: Centrum služeb pro normalizaci.

[4] DUGIN, A., JERSÁK, J., POPOV, A. (2014). Method for Determining of the Anti-adhesion Ability of Cutting Fluids. Manufacturing Technology. Rec. -. Vol. 14, June, č. 2. s. 145 - 149. ISSN 1213-2489.

[5] DUGIN, A., VOTOČEK, J., POPOV, A. (2014). Method for Determining the Tribological Properties of the Cutting Fluid. Manufacturing Technology. Rec. -. Vol. 14, June, č. 2. s. 149 - 153. ISSN 1213-2489.

[6] DUGIN, A., VOLESKÝ, L. (2014). Effect of Cutting Fluids on the Tool Life in Turning and Milling of Construction Steel. Manufacturing Technology. Vol. 14, No. 3. s. 290-296. ISSN: 1213-2489.

[7] GABRIEL, V., HOLUB, L., JERSÁK, J. (2001). Zkoušky řezných kapalin. Technik. Červen, IX, č. 6. s. 9. ISSN 1210-616X.

[8] HOLÝ, J. (2010). Řezné kapaliny a jejich použití při obrábění, [Diplomová práce]. Brno: Vysoké učení technické v Brně, $53 \mathrm{~s}$.

[9] JERSÁK, J., POPOV, A., aj. (2014). Ekologické obráběcí kapaliny nové generace. Rec. F. Holešovský. 1. vyd. Liberec: Technická univerzita v Liberci, 88 s. ISBN 978-80-7494-142-9.

[10]JERSÁK, J., REJZEK, M. (2011). Účinek procesní kapaliny na proces soustružení a vybrané parametry integrity povrchu. Strojírenská technologie. Rec. prof. Vasilko, prof. Holešovský. roč. 16, duben, č. 2. s. 17 - 23. ISSN 1211-4162.

[11]JERSÁK, J., VRKOSLAVOVÁ, L. (2013). The Influence of Process Fluids on the Properties of the Surface Layer of Machined Components. Manufacturing Technology. Rec. Lukovics, I., Vol. 13, December, No. 4. s. 466 - 473. ISSN 1213-2489.

[12]JERSÁK, J., POHOŘALÝ, M., ŽIŽKA, J. (2004). Monitoring of Grinding Process. Manufacturing Technology. Vol. 4, October, No. -, s. 45 - 48. ISSN 1213-2489. 
[13] KAPLAN, F. (2012). Metodiky zkoušek obráběcích kapalin a jejich hodnocení při čelním frézování:[Bakalářská práce]. Liberec: Liberec, TU Liberec, $57 \mathrm{~s}$.

[14]LICEK, R., POPOV, A. (2012). Návrh řezných podmínek a hodnocení vlivu procesních kapalin na tvorbu nárůstku u antikorozních ocelí. Strojírenská technologie. Rec. I. Lukovics, F. Holešovský. roč. 17, prosinec, č. 5 a 6. s. 317 326. ISSN 1211-4162.

[15] MÁDL, J., KOUTNÝ, V. (2002). How to Select Suitable Cutting Fluid. Manufacturing Technology. Vol. 2, June, č. -. s. 45 - 53. ISSN 1213-2489.

[16]MÁDL, J. (2002). Dry Machining Versus Cutting With Cutting Fluids. Manufacturing Technology. Vol. 2, June 2002, č. -. s. 42 - 45. ISSN 1213-2489.

[17] MEČIAROVÁ, J., JERSÁK, J. (2006). Humánní aspekty používání procesních kapalin. Strojírenská technologie. Rec. prof. Mádl. roč. XI, prosinec, č. 4. s. 4 - 8. ISSN 1211-4162.

[18] ČILLÍKOVÁ, M. (2008). Top trendy v obrábaní - VI. čast' - Procesné médiá.., aj. Žilina: MEDIA/ST, s.r.o., Január, ISBN 978-80-969789-3-9. 